\title{
THE SEISMIC PERFORMANCE OF THE FRAME-SHEAR WALL TALL BUILDING WITH AND WITHOUT VERTICAL SETBACK
}

\author{
Mashrah Waleed Ali Hamed ${ }^{1}$, Zhao Jianchang ${ }^{2}$, Okine Michael Nii Sarbah ${ }^{3}$ \\ ${ }^{1}$ Lanzhou Jiaotong University, Lanzhou ,730070, China \\ ${ }_{3}^{2}$ Lanzhou Jiaotong University, Lanzhou ,730070, China \\ ${ }^{3}$ Lanzhou Jiaotong University, Lanzhou,730070, China
}

\begin{abstract}
Recently, High-rise buildings are developed very quickly to satisfy the production and peoples' living needs and development. There are so many reasons for large number of developments of the high-rise building, commercialization, industrialization and urbanization. This quick development of the high-rise building necessitates study and analysis of the seismic performance of highrise buildings, especially when the high-rise building has irregularity in its horizontal plan or vertical section. In this present study, main focus to analyze the relative earthquake performance for the tower portion of a 34 storey Reinforced Concrete (RC) with 103.4m total height frame-shear wall buildings with and without setbacks subjected to an earthquake excitation scaled down to be of peak ground acceleration appropriate for China, and analyze the setback influence on this high-rise building to identify weakness positions in the high-rise building structure. The comprehensive use of SAP2000 software V16.1 for the elastic calculations aid to assess nonlinear time history analysis for their applicability to tower models (first model with setbacks, second model without setback) of height-rise frame-shear wall building under same conditions of the site category, earthquake acceleration type and standards in structural design. This study is carried out first to judge the shear for the tall building model 1 belongs to which type of the torsion, second to study how the vertical (elevation) setback impact in tall building resisting seismic activity.
\end{abstract}

Key Words: Setback; SAP2000; Irregular high-rise building; Frame-shear wall; Seismic analysis; Time history analysis.

\section{INTRODUCTION}

According to China resisting earthquake code section 3.4.2 requires that architectural design should pay attention to the influence of the inner plane design and rules on vertical section, for good seismic performance and economic values, should use regular or simple design form, use symmetric resisting lateral load element plan layout, and appropriate uniform changes of lateral stiffness along the building height, where the materials and dimensions of resisting lateral load element gradually reduce to avoid the sudden changes of the stiffness and bearing capacity, so the article 3.4.1 of the code mention the design of tall building should avoid serious irregular design forms [2]. Recently, the economy of China is developing very quickly, with the increase in the level of science and technology; also the needs of people have given designers more challenges to use more complex and irregular forms. These modern buildings are almost always irregular, their appearances are not only with a new look to the urban construction and planning; but also they bring serious challenges to the engineering design. So how we can carry out appropriate seismic design and the calculation of irregular building structure according to the standards, in fact it is an important problem in engineering design [3].

\subsection{Irregular characteristics of the building structure}

In this section, I will talk about the main four irregular characteristics of the building structure. According to the code standard of resisting seismic design control parameters of irregular building structure article 3.4.3 the four main irregular characteristics of the building structure are shown below:

- Horizontal structural plan irregularity: Irregular torsion, irregular concave convex shape and discontinuous slab.

- Structure vertical irregularity: Lateral stiffness irregularity and the resisting lateral load element discontinuity.

- Complex tall building structure: have more than one tower tall building, staggered floor, has transfer floor tall building

- Exceed the standard structure: Super high structure, exceed height standard structure, super limited structure, exceed any other fixed limit standard value and new type structure, for example use of new materials or new technology or new structural form [24]. 


\subsection{Including Control Parameters For Irregular Building Structures}

Period ratio, displacement ratio (drift), storey shear bearing capacity ratio and stiffness ratio; this study will present and calculate some of these parameters [4-5].

The case study of the live high-rise building has the frameshear wall structural system to satisfy the structural and functional requirements. Frame-shear wall system is a dual constituted system in horizontal plan by adding certain number of shear wall in horizontal direction (x), vertical direction (y) or on both of the axes of the framework. In general, frame structure has a flexible layout and is made of good ductility, very easy to satisfy the requirements of the different architectural functions and space design. When the stiffness of frame structural system is small; consequently, resisting horizontal or dynamic loads ability of frame structure system is very low. While shear wall structural system stiffness is large; consequently, resisting horizontal or dynamic loads capacity is very high, But because the horizontal distance between the shear walls make the building layout not flexible enough, frame-shear wall structure with both structural systems, frame system and shear-wall system combines to make the building layout more flexible, has freedom of space design and appropriate lateral stiffness for the whole structure, with good seismic performance, so this kind of structural system has been widely used in high-rise buildings [1-6].

\section{THE CONCEPT OF TALL BUILDING STRUCTURE}

\subsection{Real Live Lanao Huayuan Tall Building Model Description (Model 1)}

The concept of real live Lanao Huayuan tall building; the live project lanao huayuan construction is located in China, Gansu Province, Lanzhou City, Chengguan District, the intersection between the Xiguan Yongchang road and the Zhangye Road, on the northwest corner of pedestrian Street cross,. The total land area used for this project is $6213.20 \mathrm{~m} 2$, and the total constructed area is $48306.70 \mathrm{~m} 2$, the building basal area is $2759.5 \mathrm{~m} 2$, underground (basement) constructed area is $6140.4 \mathrm{~m} 2$, the total construction floor area on ground is $41896.3 \mathrm{~m} 2$. This live project structure has 34 upper floors and the total height of constructed project has $104.3 \mathrm{~m}$. From the first to fifth floors have commercial functions, sixth floor is a property floor, and from seventh to thirty-first are residential floors. The structural system of this project is a frame shear wall structure system; Structural safety level is level two, resisting seismic fortification intensity is level 8 , the design resisting earthquake basic acceleration value is $0.20 \mathrm{~g}$, resisting seismic class of shopping malls floors for class B ( 乙), Seismic class of residential storey for C (丙)class, shear wall resisting seismic level is level one, rating of building for fire resistance is of first class, and rating of the basement fire resistance is also of first class, the basement for level of waterproof is that of level one.
Architectural design concept of the lanao huayuan construction; floor plan setbacks; lanao huayuan tall building plans have horizontal setbacks at different height levels, as shown in Fig.1 and Fig.2. We can see the different setbacks, the first horizontal setback is applied to lower five plans (storey 1-5), second horizontal setback is applied to the sixth floor of the high-rise building as shown in Fig.2, these two setbacks are applied to the commercial part of this tall building. The tower of the residential part of this tall building (7-31 storeys) has no horizontal setback on the plan, as shown in Fig.2. The setback in the lower part of the lanao huayuan tall building belongs to the $\mathrm{L}$ shape of the setback, so it follows the rule of the L shape in the Chinese code for the length of the protuberant part of the setback under a level 8 or 9 earthquake must to be as follow in equations (1) and (2):

$$
l / b \leq 1.5
$$

Or

$$
l / B_{M A X} \leq 0.3 .
$$

Lanao Huayuan tall building has many horizontal setbacks on the floor plan of lower commericial part (base part) this make the tall building more complex and irregular [1]. On the other hand the residential part of the tall building (tower part) actually has a regular floor plan design.

\subsection{Lanao Huayuan Tall Building Vertical Setback}

Vertical setback on $\mathrm{X}$ direction: the lanao huayuan tall building has two vertical setbacks along of its total height, the first setback is on the sixth floor level at a height of $26.1 \mathrm{~m}$, the tall building moved back in both right and left sides (unsymmetric setback; $15 \mathrm{~m}$ on the right side and 4.8 on the left side), the second setback is on the 31 floor level at 98.6 height, the tall building moved back also on the right and left sides(symmetric setback;7.4m on both sides) as shown in Fig. 1 and Fig.2.

Vertical setback on y direction: the setback on y direction has three setbacks, first one is in the right side, at fifth floor level setback 1 ; it is unsymmetrical ( $14.4 \mathrm{~m}$ in the right side), the other two setbacks are on the sixth floor level and the thirteeth one floor level; setback 2,3, also can be said to be symmetrical with setbacks $(7.5 \mathrm{~m}$ in the right side and $7.5 \mathrm{~m}$ in the left side) as shown in Fig.1 and Fig.2.

When the tall building has a setback, then it must follow the setback code rules, so we can submit the project according to Chinese rules. The height of base to the total height of the tall building must be more than 0.2 in this live project. The height of the base to the total height of the tall building equal 0.26 that is bigger than ratio in the code. And the adduction part width to the total width ot the tall building must be more than 25\%; we can see the setbacks on $\mathrm{X}$ direction doesn't meet the setback rules in chinese code, on the other hand the first and second setbacks on Y direction is meeting with chinese code $19 \%$ and $20 \%$, the third setback in the tall building peak doesn't meet the setback rules in the chineses code, whether the ratio of base to total height of the tall building or the adduction part width to the total width ot the tall building. 


\subsection{Lanao Huayuan Tall Building Height;}

Lanao Huayuan has a different storey height which can be divided into groups, the commericial part 1-3 storeys; height for each storey $=4.5 \mathrm{~m}$ and $4-6$ storeys height $=4.2 \mathrm{~m}$. The residential part of the tall building; 7-31 storeys; height for each storey $=2.9 \mathrm{~m}$. Service storeys; 32 and 34 storeys $=3 \mathrm{~m}$ for each storey, storey $33=1.8 \mathrm{~m}$ height;taal building total height $=104.3 \mathrm{~m}$ as shown in Fig. 1 .

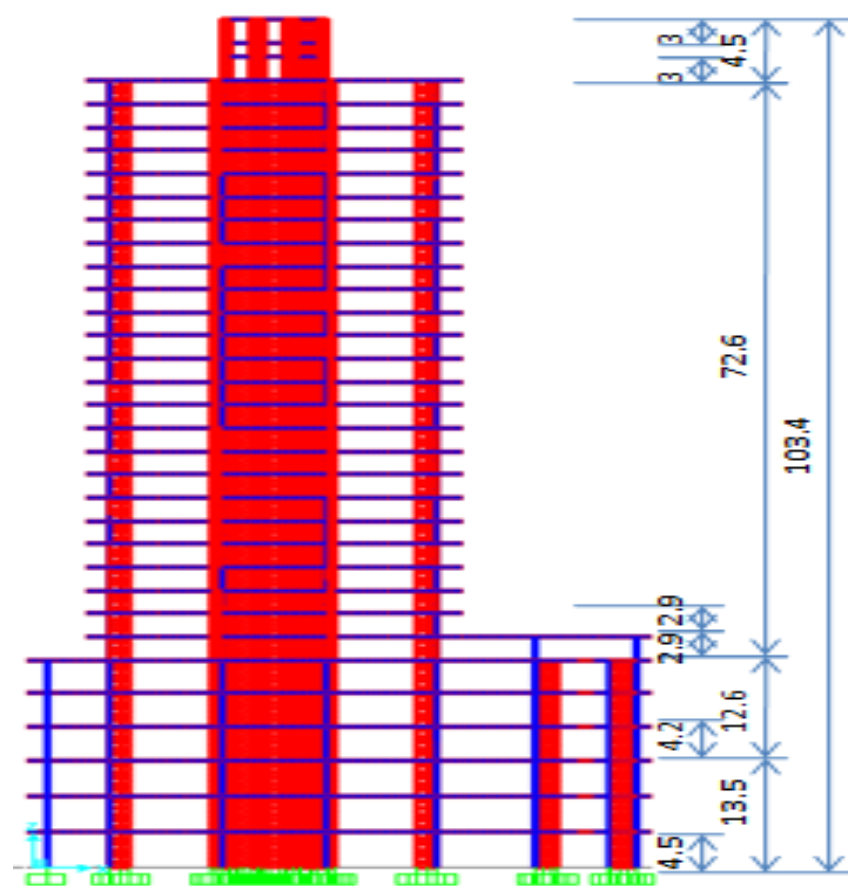

Fig.1.Model 1 vertical section

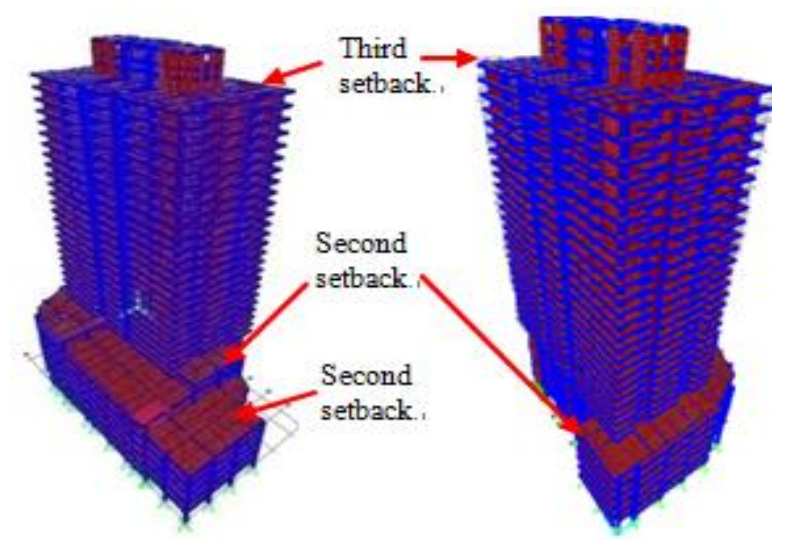

Fig.2. Model 1 views

\subsection{Lanao Huayuan Tall Building Optimized Model 2}

The second model of the high-rise building has the same design functions and specifications; the only difference is that all the irregular setbacks of the horizontal plan have been eliminated as shown in Fig.1 and Fig.2 to get the regular tower part of the high-rise building without setbacks as shown in Fig.3.

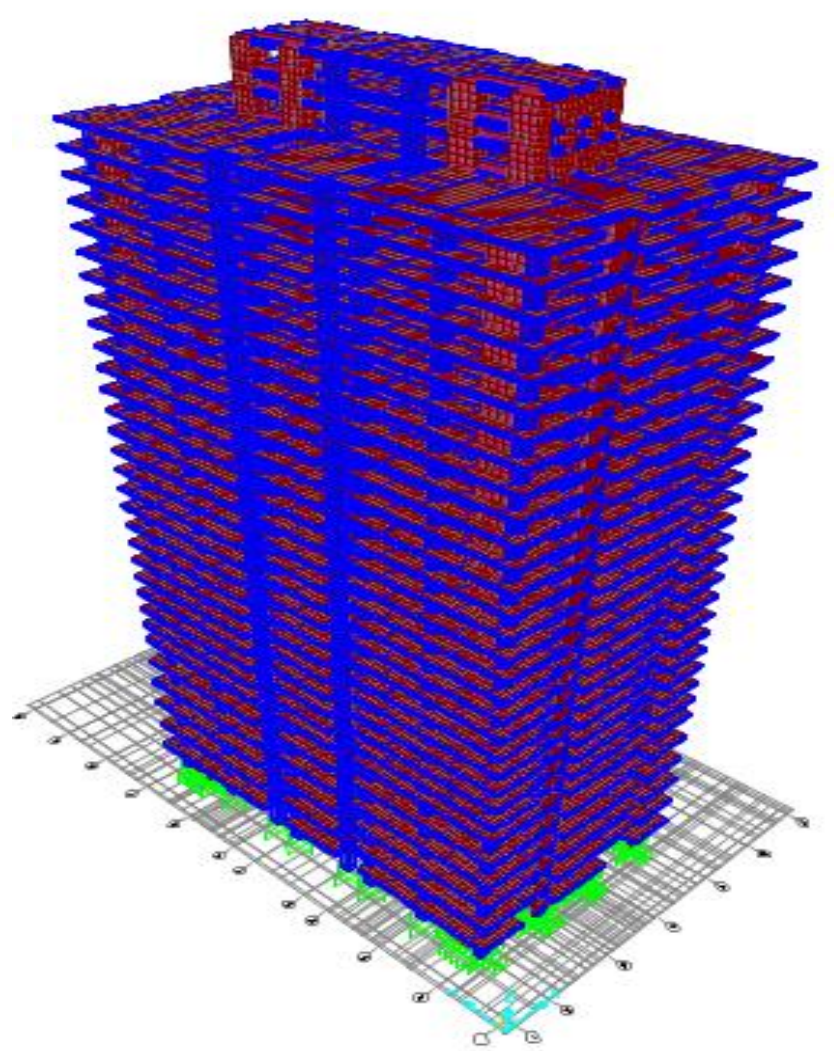

Fig.3. Model 2 view

\section{THE ANALYSIS RESULT}

The accuracy of the proposed analysis equations is verified by using nonlinear elastic-plastic time history analysis of 3D reinforced concrete frame-shear wall models in SAP2000 v16.1. The analysis will exist in tow models as shown in Fig. 1 above by using time history analysis, applying El Centro acceleration on $\mathrm{X}$ direction (EQX) and $\mathrm{y}$ direction (EQY) to the models. After analysis is done, the results of the part of tower of the model 1 seismic response result are considered in this study to compare with the model 2 seismic response results to show how the setbacks impact on the high-rise building for resisting seismic ability.

Elastic-plastic analysis execution to this study analysis according to china building design code (GB50011-2001) and technical specification for tall building concrete structure (JGJ 3-2002) dynamic elastic plastic analysis is executed to the tow building because the tall building vertical irregularity and the tall building height is more than $100 \mathrm{~m}$ in 7,8 degree seismic zone area [7],[8]. So the time history nonlinear analysis is carried out to run tall building dynamic elastic-plastic analysis.

\subsection{The Models Displacement Result Analysis:}

The displacement result shown in the models have a total displacement of $\boldsymbol{\delta}$, the model 1 storey displacement average $\mathbf{A}=($ storey $\max \delta+$ storey $\min \delta) / 2$, both models storey drift $\Delta \mathbf{u}$, model 1 storey drift angle $\theta$, and model 1 ratio of storey displacement and storey displacement average $\delta / \mathrm{A}$. 

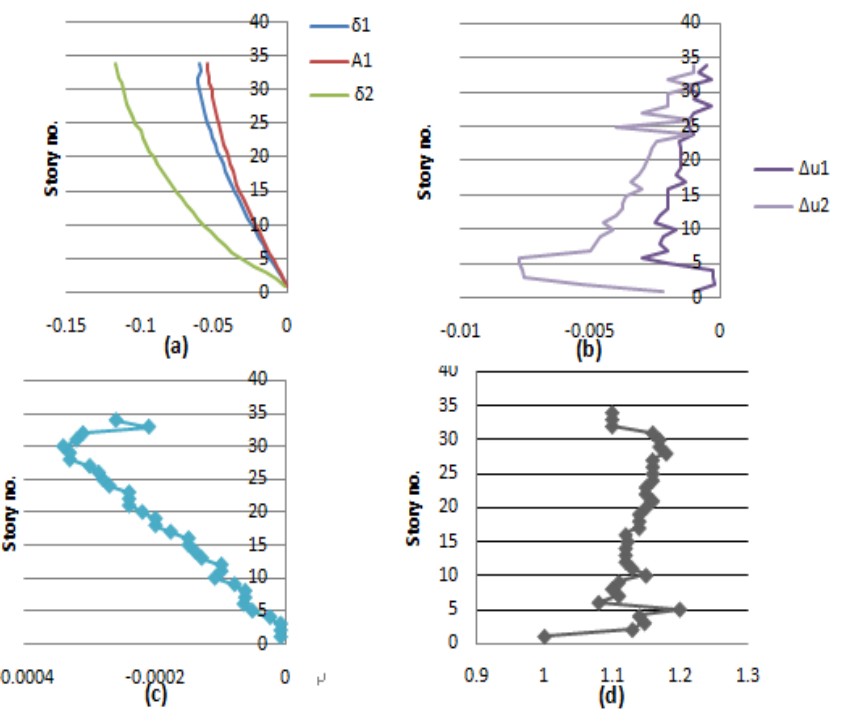

The Analysis For The Max Displacement Of EQX On X Direction: Model 1 EQX Max $\delta_{1}=0.042 \mathrm{~m}$ In The Same Time Model 2 Max $\delta_{2}=0.023 \mathrm{~m}$, Fig. 4.A. Model 1 Max $\Delta \mathrm{u}_{1}=0.00151$ With Storey Drift Angle $\theta_{1}=1 / 2780$ In $5^{\text {th }}$ Floor While Model $2 \operatorname{Max} \Delta \mathrm{u}_{2}=0.00165^{\text {th }}$ With Storey Drift Angle $\theta_{2}=1 / 2625$ In $5^{\text {th }}$ Floor, Fig. 4.B. Model 1 Max Plan Torsion Angle $\theta_{11}=0.000056 \mathrm{Rad}$ In $31^{\text {th }}, 32^{\text {th }}$ Floor Fig. 4.C And The Max Ratio Of $\delta_{1} / \mathbb{A}_{1}=1.06$ In $12^{\text {th }}$ Floor Fig. 4.D.

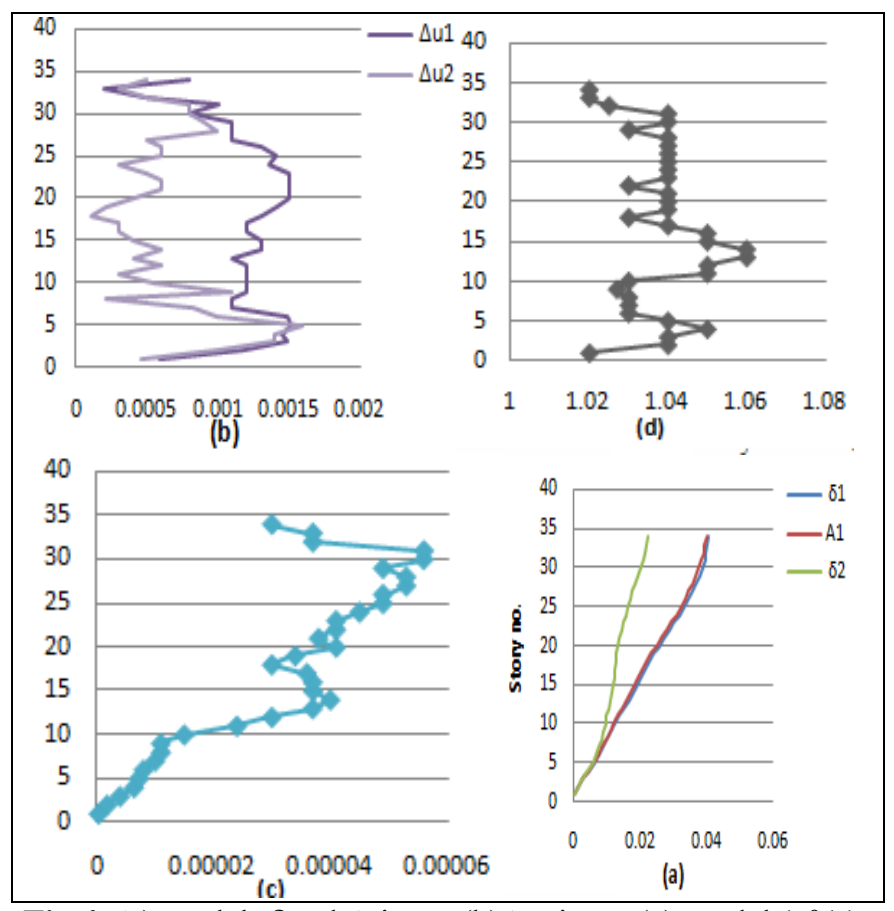

Fig.4. (a) models $\delta$ and $\mathrm{A}$ in $\mathrm{m}$, (b) $\Delta \mathrm{u}$ in $\mathrm{m}$, (c) model $1 \theta 11$ in $\mathrm{rad},(\mathrm{d})$ model $1 \delta / \mathrm{A}$ ratio

- The Analysis For Minimum Displacement Of EQX On X Direction: Model 1 EQX Maximum ${ }^{\delta_{1}}=0.06 \mathrm{~m}$ In

The Same Time Model 2 Maximum $\delta_{2}=0.0117 \mathrm{M}$, Fig. 5.A. Model 1 Maximum $\Delta \mathrm{u}_{1=0.002}$ With Storey Drift Angle $\theta_{1=1 / 2100}$ In 6th Floor While Model 2 Maximum $\Delta \mathrm{u}_{2}=0.0077$ In 5th And 6th With Storey Drift Angle $\theta_{2=1 / 545}$ In 5th Floor, Fig. 5.B. Model 1 Maximum Plan Torsion Angle $\theta_{11}=.00034 \mathrm{Rad}$ In 30th, Floor Fig. 5.C And The Maximum Ratio Of $\delta_{1 / A_{1}=1.2}$ In 5th Floor Fig. 5.D.Fig.5. (a) models $\delta$ and $\mathrm{A}$ in $\mathrm{m},(\mathrm{b}) \Delta \mathrm{u}$ in $\mathrm{m}$, (c) model 1011 in rad, (d) model $1 \delta /$ A ratio

- The analysis for the maximum displacement in the $\mathrm{Y}$ direction: model $1 \mathrm{EQY}$ has a maximum $\delta_{1}=0.034 \mathrm{~m}$ and model 2 maximum $\delta_{2}=0.024$ m, Fig. 6.a. Model 1 has maximum $\Delta \mathrm{u}_{1}=0.0015 \mathrm{~m}$ with storey drift angle $\theta_{1}=1 / 2800$ in $3^{\text {th }}, 4^{\text {th }}$ and $5^{\text {th }}$ floor while model 2 has maximum $\Delta \mathrm{u}_{2}=0.0013 \mathrm{~m}$ in $5^{\text {th }}$ and $6^{\text {th }}$ with storey drift angle $\theta_{2}=1 / 3200$ in $6^{\text {th }}$ floor, Fig. 6.b. Model 1 maximum plan torsion angle $\theta_{11}=0.000083 \mathrm{rad}$ in $30^{\text {th }}$ and $30^{\text {th }}$ floor Fig. 6.c. The maximum ratio of $\delta_{1} / A_{1}=1.06$ in $27^{\text {th }}-31^{\text {th }}$ floor Fig. 6.d.
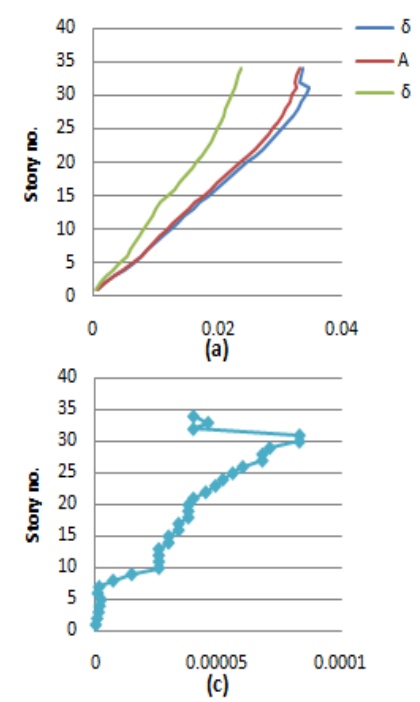

Fig.6. (a) models $\delta$ and $\mathrm{A}$ in $\mathrm{m},(\mathrm{b}) \Delta \mathrm{u}$ in $\mathrm{m}$, (c) model $1 \theta 11$ in $\mathrm{rad},(\mathrm{d})$ model $1 \delta / \mathrm{A}$ ratio

- The analysis for the minimum displacement in $\mathrm{Y}$ direction: Model $1 \mathrm{EQY}$ has minimum $\delta_{1}=0.0395 \mathrm{~m}$ and model 2 has minimum $\delta_{2}=0.068 \mathrm{~m}$, Fig. 7.a. Model 1has minimum $\Delta \mathrm{u}_{1}=0.0018$ with storey drift angle $\theta_{1}=1 / 2333$ in $5^{\text {th }}$ floor while model 2 has maximum $\Delta \mathrm{u}_{2}=0.0043$ in $5^{\text {th }}$ with storey drift angle $\theta_{2}=1 / 976$ in $6^{\text {th }}$ floor, Fig. 7.b. Model 1 has maximum plan torsion angle $\theta_{11}=.000076 \mathrm{rad}$ in $30^{\text {th }}$ and $30^{\text {th }}$ floor Fig. 7.c. The maximum ratio of $\delta_{1} / A_{1}=1.15$ in $5^{\text {th }}$ floor Fig. 7.d. 

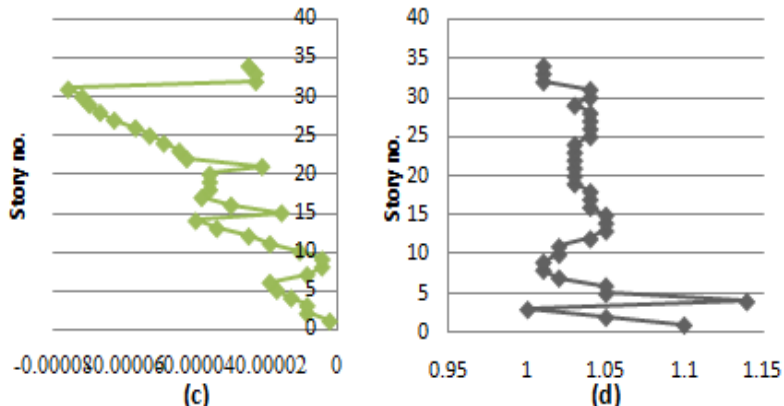

(c)

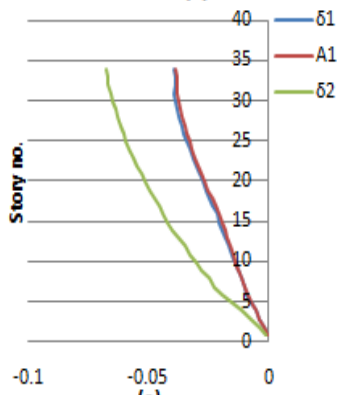

(a)

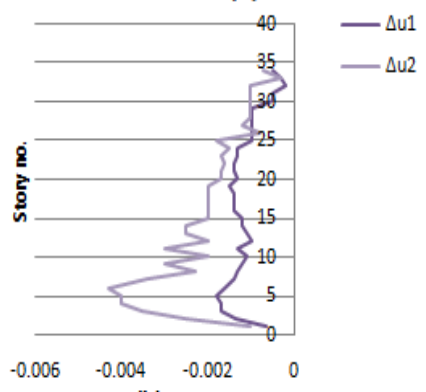

(b)

Fig.7. (a) models $\delta$ and $\mathrm{A}$ in $\mathrm{m},(\mathrm{b}) \Delta \mathrm{u}$ in $\mathrm{m}$, (c) model 1011 in $\mathrm{rad},(\mathrm{d})$ model $1 \delta / \mathrm{A}$ ratio

\subsection{The Models Frame Column Seismic Load}

\section{And Internal Forces Result Analysis:}

- The Analysis For The Maximum Internal Forces In X Direction: Firstly, The Mode L Has Maximum $\mathrm{P}=884$ tonf $>$ Model 2 Maximum $\mathrm{P}=489$ tonf $\mathrm{By} 1.8$ Times As Shown In Fig. 8.A. Secondly, The Shear Forces Of The Model Has Maximum $V_{1}=175$ tonf > Model 2which Has Maximum $V_{2}=89$ tonf By 1.96 Times. Thirdly, The Model $1 \mathrm{~T}=22$ tonf $>$ Model 2 $\mathrm{T}=17$ tonf By 1.29 Times. Finally, The Maximum Moment Of The Tower Models In X Direction Is 284tonf For Model1 $\mathrm{M}_{1}$ And 229tonf For Model $2 \mathrm{M}_{2}$, So Model1 $\mathrm{M}_{1}>$ Model $2 \mathrm{M}_{2}$ By 1.24 Times, As Shown In Fig. 8.B.

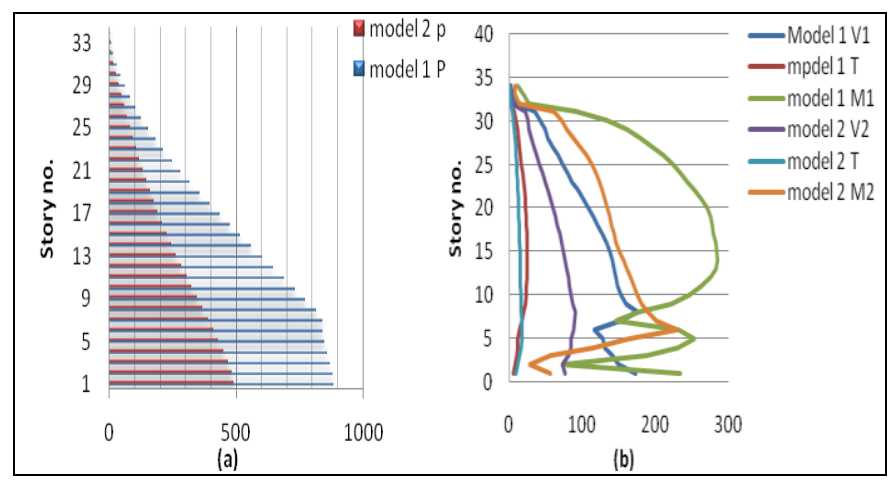

Fig.8. (a) Models earthquake load forces $\mathrm{P}$ in tonf, (b) models internal forces in tonf and tonf $/ \mathrm{m}$.

- The analysis on the minimum internal forces in the $X$ direction: Firstly, the mode 1 has maximum $\mathrm{P}=951$ tonf $>$ model 2 having maximum $\mathrm{P}=534$ tonf by 6 times as shown in Fig. 9.a. Secondly, the shear forces of the mode 1 maximum $V_{1}=102$ tonf $>$ model 2

maximum $V_{2}=16$ tonf by 1.96 times. Thirdly, the model $1 \mathrm{~T}=26$ tonf $<$ model $2 \mathrm{~T}=30$ tonf by0. 8 times. Finally, the maximum moment of the tower models in $\mathrm{X}$ direction is 432tonf for model1 $\mathrm{M}_{1}$ and 381tonf for model $2 \mathrm{M}_{2}$, so model1 $\mathrm{M}_{1}>$ model $2 \mathrm{M}_{2}$ by 1.13 times, as shown in Fig. 9.b.

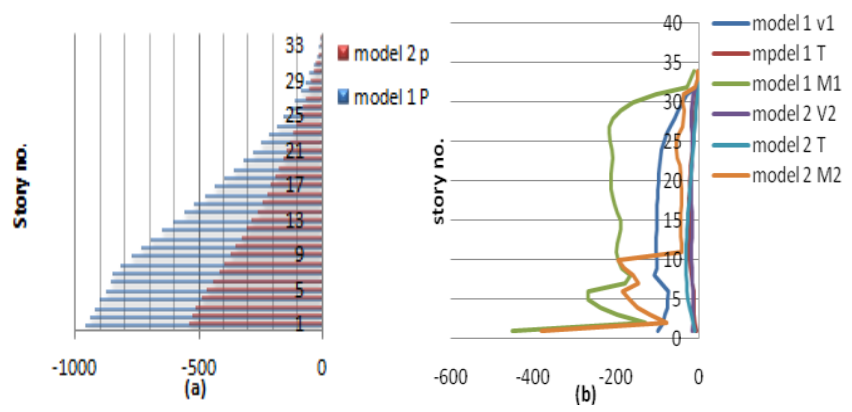

Fig.9. (a) Models earthquake load forces $\mathrm{P}$ in tonf, (b) models internal forces in tonf and tonf./m

- The maximum internal forces analysis on $\mathrm{Y}$ direction: First, the mode 1 max $\mathrm{P}=417$ tonf $>$ model $2 \max$ $\mathrm{P}=313$ tonf 1.3 times as shown in Fig. 10.a. Second, the shear forces of the model max $V_{1}=170$ tonf $>$ model 2 $\max V_{2}=36$ tonf 4.7 times. Third, the model $1 \max$ $\mathrm{T}=40$ tonf $>$ model $2 \mathrm{~T}=3.5$ tonf 11 times. Finally, the max moment of tow models on $\mathrm{x}$ direction is 263tonf/m for model1 $\mathrm{M}_{3}$ and 106tonf/m for model2, so model1 $\mathrm{M}_{3}>$ model $2 \mathrm{M}_{3}$ 2.5times, as shown in Fig. 10.b.

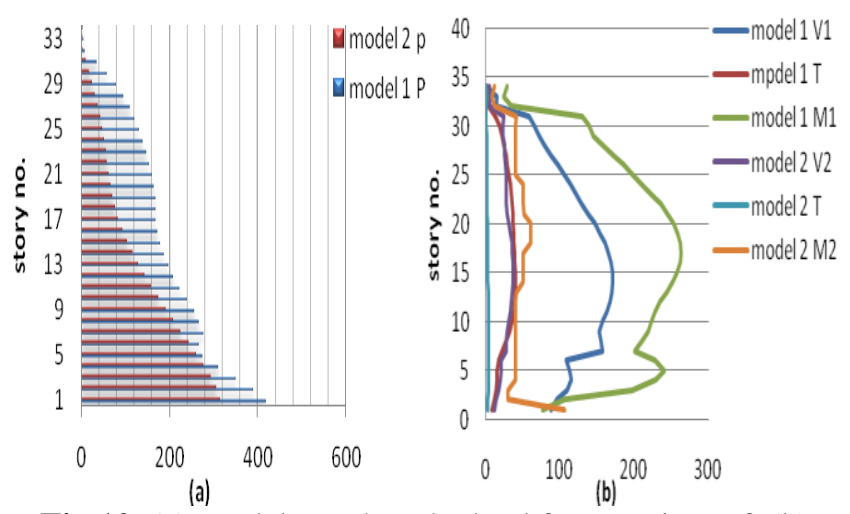

Fig.10. (a) Models earthquake load forces $\mathrm{P}$ in tonf, (b) models internal forces in tonf and tonf $/ \mathrm{m}$.

- The analysis on the maximum internal forces in the $\mathrm{Y}$ direction: Firstly, the model 1 has a maximum $\mathrm{P}=417$ tonf $>$ model 2 has maximum $\mathrm{P}=313$ tonf 1.3 times as shown in Fig. 11.a. Second, the shear forces of the model maximum $V_{1}=170$ tonf $>$ model 2 maximum $V_{2}=36$ tonf 4.7 times. Third, the model 1 maximum $\mathrm{T}=40$ tonf $>$ model $2 \mathrm{~T}=3.5$ tonf 11 times. Finally, the maximum moment of tower models on $\mathrm{x}$ direction is 263tonf/m for model1 $\mathrm{M}_{1}$ and 106tonf/m for model $2 \mathrm{M}_{2}$, so model1 $\mathrm{M}_{1}>$ model $2 \mathrm{M}_{2}$ 2.5times, as shown in Fig. 11.b. 


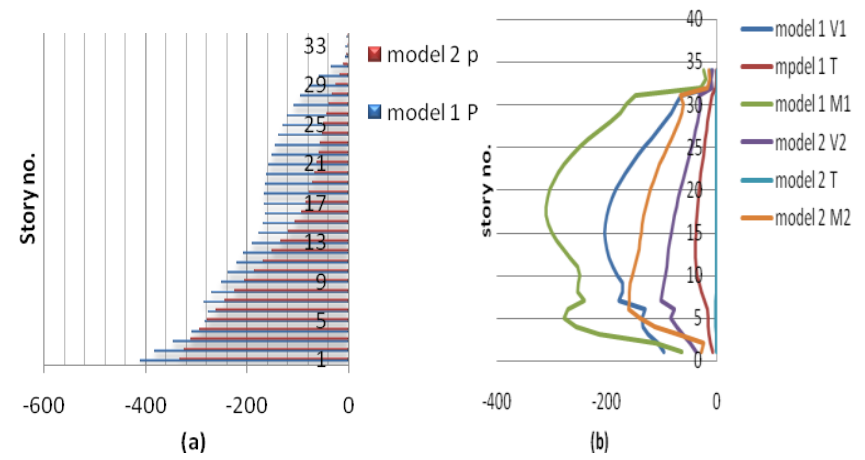

Fig.11. (a) Models earthquake load forces $\mathrm{P}$ in tonf, (b) models internal forces in tonf and tonf $/ \mathrm{m}$.

\subsection{The Result Analysis Of Internal Forces For The}

\section{Model Frame Special Beams}

To show how the setback impacts on the frame beams of the model 1 , beam 1 on $\mathrm{X}$ axis and beam 2 on $\mathrm{Y}$ axis analysis results are picked out to show the different results for the tower models as shown in Fig. 12.a and Fig. 12.b. The results are shown in four sections $\mathrm{a}, \mathrm{b}, \mathrm{c}$ and $\mathrm{d}$, each section has maximum and minimum earthquake load $\mathrm{P}$ and maximum and minimum internal forces graphs as graphed in Fig. 14, Fig. 15, Fig. 16 and Fig. 17.

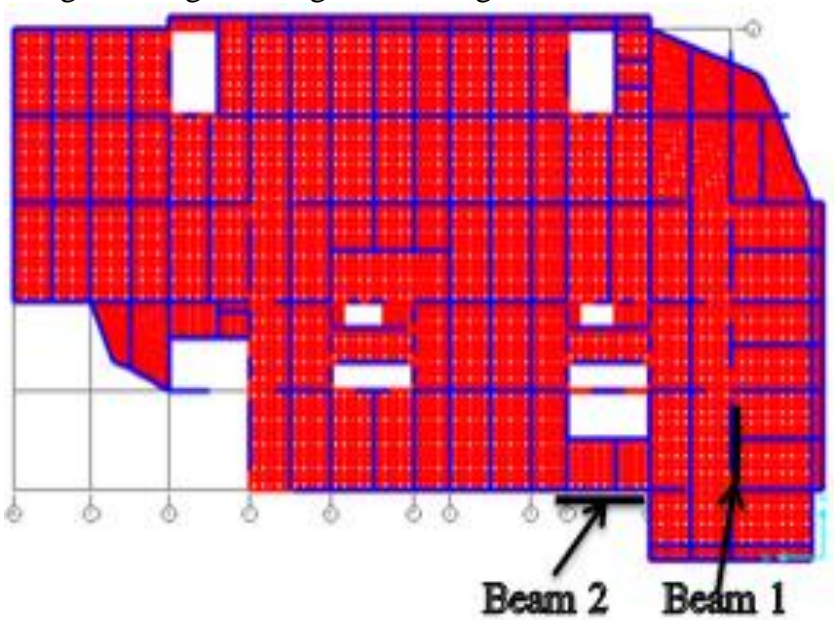

Fig.12. Model 1 plan

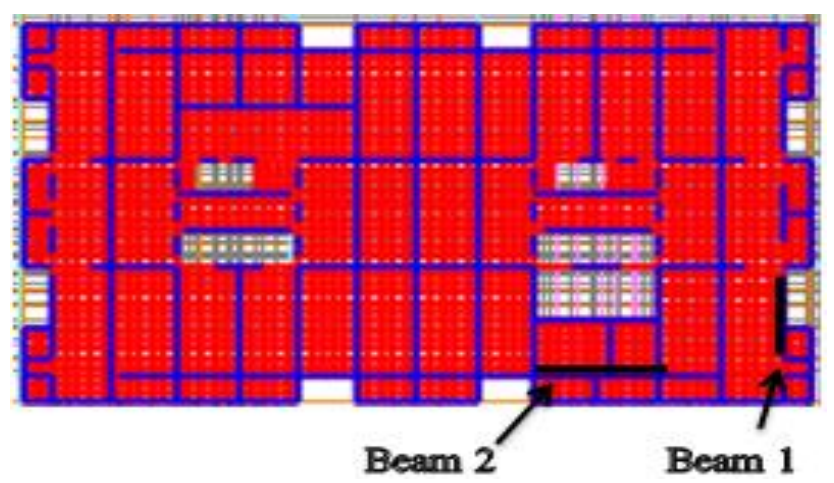

Fig.13. Model 2 plan

- Iinternal force analysis of beam1of the models maximum and minimum $\mathrm{X}$ directions
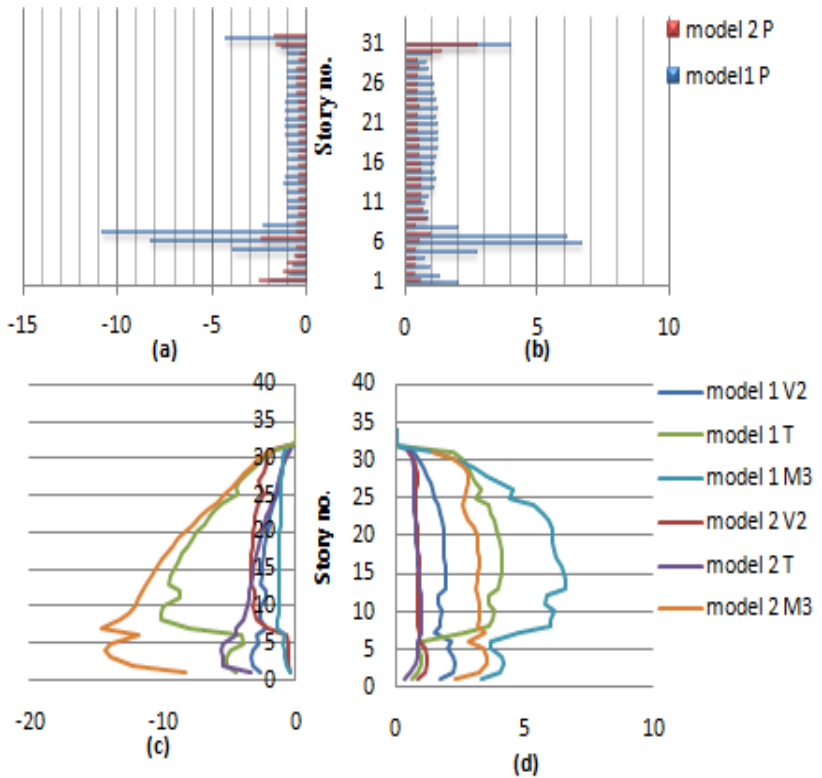

Fig.14. (a), (b) Models beam 1 EQX min and max earthquake load forces $\mathrm{P}$ in tonf, (c).(d) $\min$ and $\max$ internal forces in tonf and tonf $/ \mathrm{m}$.

Internal force analysis of Beam 2 of the models maximum and minimum $\mathrm{X}$ direction

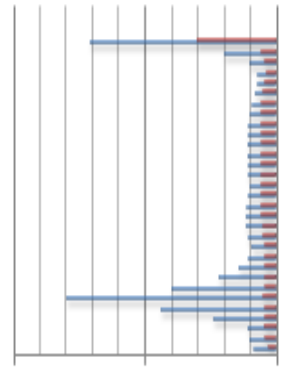

$-40$

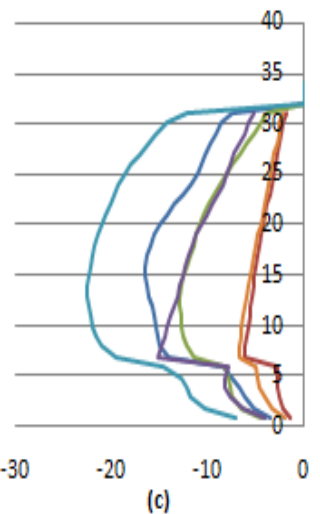

Fig.15. (a), (b) Models beam 2 EQX min and max earthquake load forces $\mathrm{P}$ in tonf, (c).(d) min and max internal forces in tonf and tonf $/ \mathrm{m}$. 


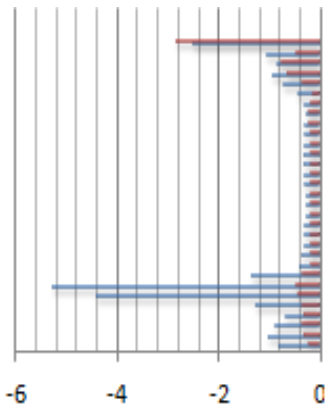

(a)

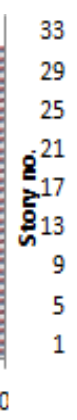

33
29
25
$8^{21}$
17
$8_{13}^{13}$
9
5
1
0

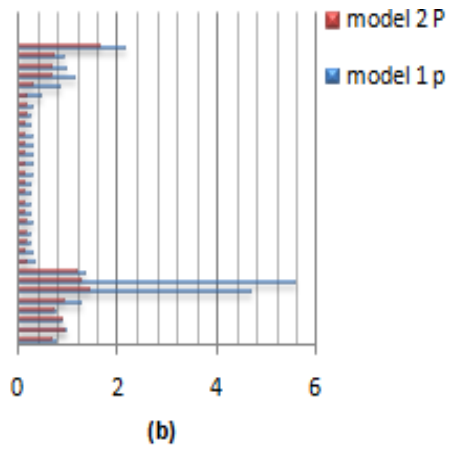

Internal forces of analysis on Beam 1of the models maximum and minimum $\mathrm{Y}$ direction

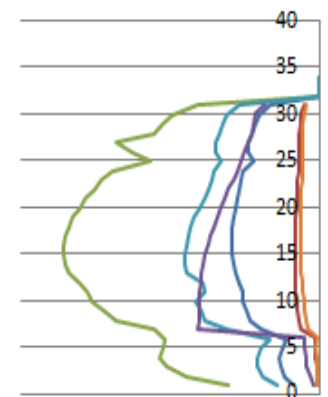

$-10$

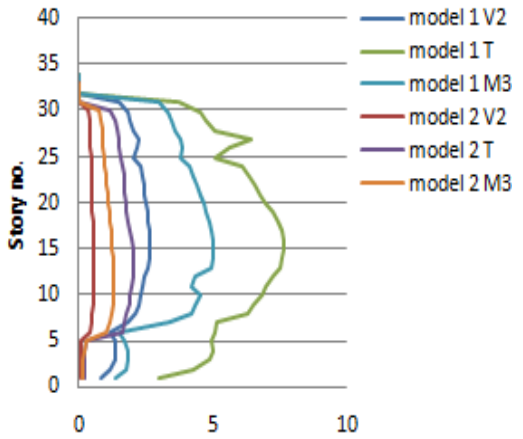

(d)
Fig.16. (a), (b) Models beam 1 EQY min and max earthquake load forces $\mathrm{P}$ in tonf, (c).(d) min and max internal forces in tonf and tonf $/ \mathrm{m}$.

Internal forces of analysis on Beam 2of the models maximum and minimum $\mathrm{Y}$ direction

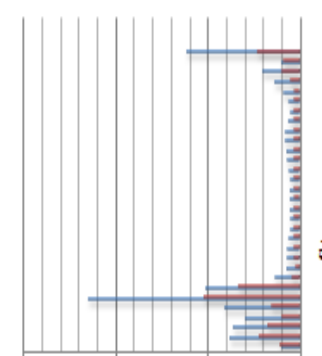

$-60$
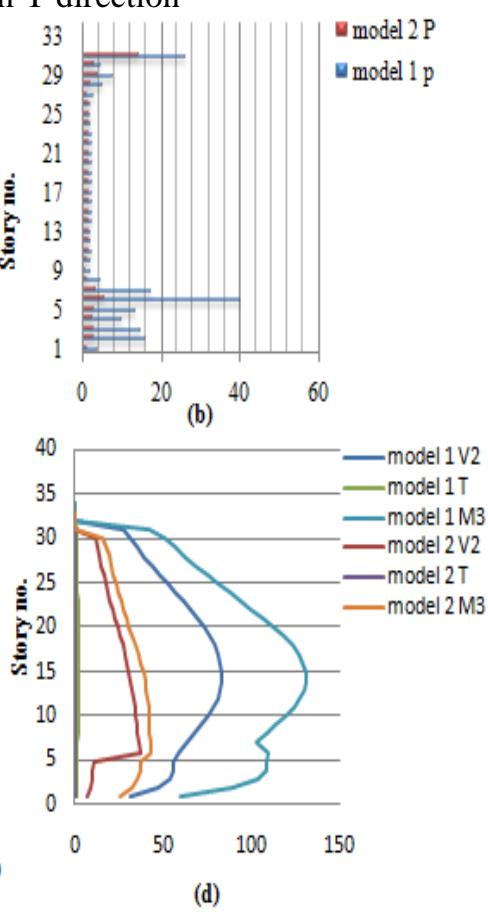

(d) (c)

Fig.17. (a), (b) Models beam 2 EQY min and max earthquake load forces $\mathrm{P}$ in tonf, (c).(d) min and max internal forces in tonf and ton/mf.

\subsection{The Model Base Foundation Reactions}

This section of the study is presenting the models base forces (reactions) including maximum EQX, minimum EQX, maximum EQY and minimum EQY of the column bases and shear wall bases to show setback impact on the models on $\mathrm{X}$ and $\mathrm{Y}$ and $\mathrm{Z}$ axis as shown in Fig. 18 and Fig. 19.The last graph Fig. 20 shows the bases total maximum reactions forces of model 1 and model 2 and shows the difference between both of it. The result of dynamic nonlinear analysis for both model cases is shown the different ratios of the reaction forces for model 1 and model 2 where maximum ratios of moel1 and model 2 in order are model $\mathrm{F} 1<\operatorname{modelF} 2$ by $5 \%$, model $1 \mathrm{~F} 2>\operatorname{model} 2$ by $1 \%$, mode $1 \mathrm{~F} 3>$ model 2 by $17 \%$, model $1 \mathrm{M} 1<\operatorname{mode} 2 \mathrm{M} 1$ by $32 \%$, model $1 \mathrm{M} 2>$ model $2 \mathrm{M} 2$ by $248 \%$ and model 1 M3>model2 M3 by $27 \%$.
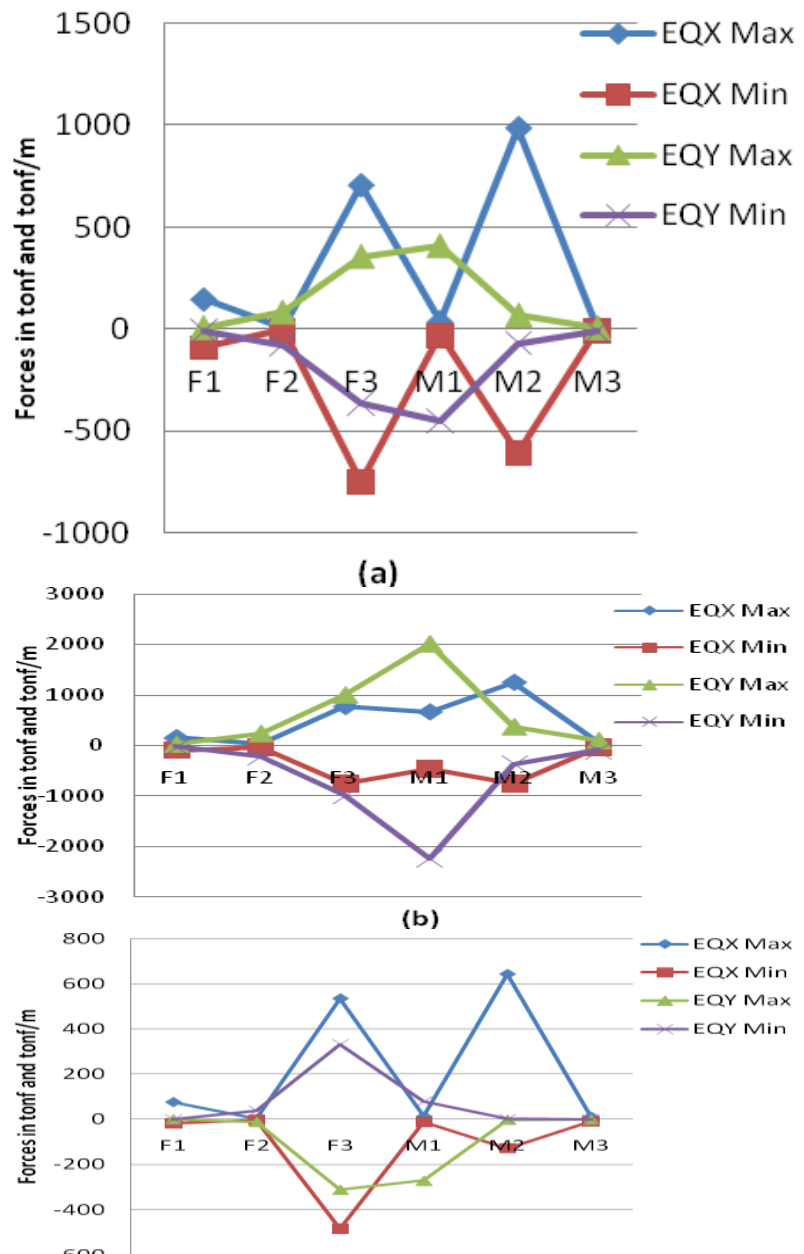

(c)

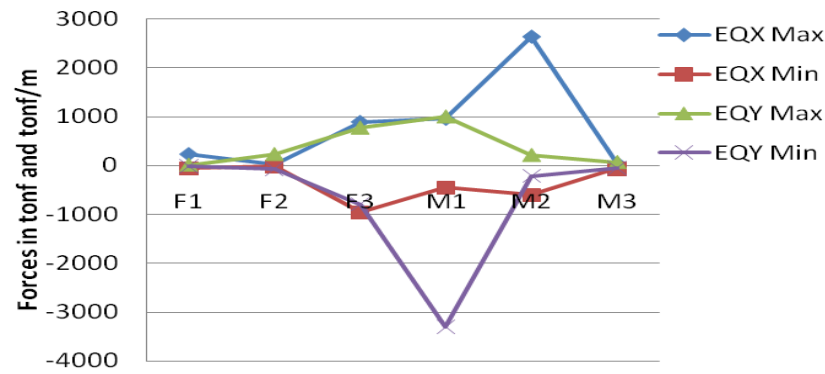

(d)

Fig.19. (a) Model 2 column base max min forces, (b) model 


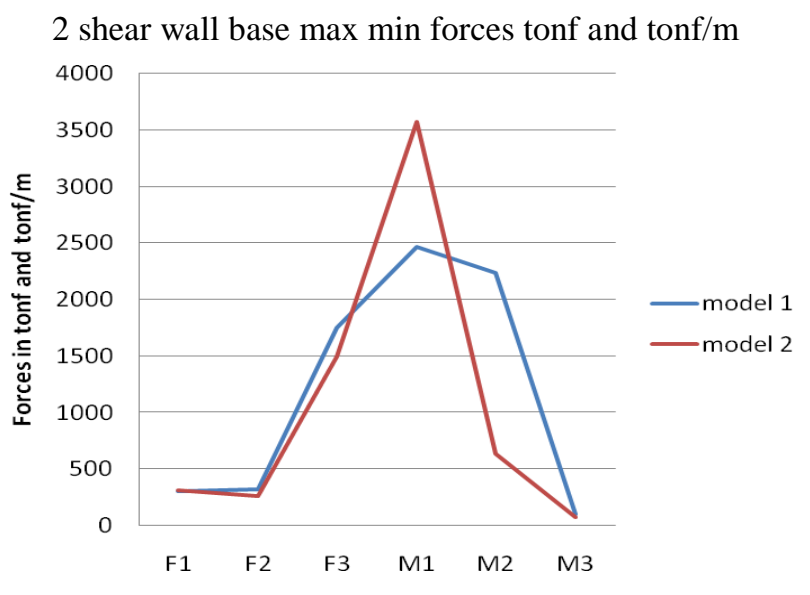

Fig.20. Model 1 and model 2 total max base reactions forces compare

\section{CONCLUSIONS}

Due to the knowledge of seismic activities in china, the buildings especially tall building structures are designed considering all seismic loads and standards, therefore I exploit this point to study considered seismic load on standard tall building in seismic performance with and without setbacks to show how the setback are impacting on the frame and bases of the frame-shear wall tall buildings displacement and internal forces as shown in graphs above. The obtained results of this study are presenting the models seismic performance results as following:

The allowable peak displacement, storey drift, storey drift angle and ratio of storey displacement and storey displacement average $\delta / \mathrm{A}$. of the tall buildings with $104.3 \mathrm{~m}$ height in order are $0.125 \mathrm{~m},(0.0052$ for commercial storeys and .0036 for residential storeys), 1/800 and 1.2. The torsion angle is depend on $\delta / \mathrm{A}$ average, so when we look into displacement analysis result of the tall building models seismic performance we can see the tower models biggest values of the displacement factors are in minimum EQX on $\mathrm{X}$ axial negative direction except model 2 tower-eight storey drift, other factors meet the standards in the Chinese code. In the same time we can observe model 1 biggest displacement is minimum EQX models displacement, model $1 \delta_{1}<$ model $2 \delta_{2}$ by $49 \%$, model $1 \Delta u_{1}<$ model $2 \Delta u_{2}$ by $74 \%$, model 1 total $\theta_{11}=0.00008 \mathrm{rad}, \delta_{1} / A_{1}$ and $=1.2$ this mean the model 1 torsion belongs to the irregular torsion, on the other hand, model $2 \theta_{11}$ and $\delta_{1} / A_{1}$ are very small so has no torsion. We can find the biggest displacement values for the model 1 in the storeys have setbacks(4-7 storey), at the same time the displacement of model 1 with setback is smaller than displacement of model 2 without setback, this means when the setbacks are applied to the tall buildings it reduces the displacement as shown above.

From the graphs above we can observe that the seismic load force $\mathrm{P}$ and other internal forces for tower model frame columns have differences, generally model $1 \mathrm{P}$ and other internal forces $\mathrm{V} 1, \mathrm{~T}$ and $\mathrm{M} 1$ are bigger than model $2 \mathrm{P}$ and other internal forces V2, T, M2 At the same time, model 1 beam 1 and model $2 \mathrm{P}$ and $\mathrm{V} 2, \mathrm{~T}$ and $\mathrm{M} 3$ are bigger than model $2 \mathrm{P}$ and V2, T and M3. At the same time the tall building columns and shear wall bases reactions forces except F1, M1 generally model 1 base reaction forces are bigger than the model 2 bases reactions forces. As described above it is clearly proven how the setback impact on the tall building seismic loads forces and internal forces where the seismic $\mathrm{P}$ and the internal are increased by applied setback to the tall building design. It is advisable to consider the setback impact from every aspect to avoid any weakness in the tall building resisting seismic performance and consider the internal forces with sudden changes in the setback storeys.

\section{SYMBOLS LIST}

\begin{tabular}{|c|c|}
\hline & All symbols as shown in table (1). \\
\hline Symbol & Expression \\
\hline$\delta_{1}$ & Model 1 maximum displacement \\
\hline$\delta_{2}$ & Model 2 maximum displacement \\
\hline$\Delta \mathrm{u}_{1}$ & Model 1 storey drift \\
\hline$\Delta u_{2}$ & Model 2 storey drift \\
\hline$\theta_{1}$ & Model 1 storey drift angle \\
\hline$\theta_{2}$ & Model 2 storey drift angle \\
\hline$\theta_{11}$ & Model 1 torsion angle \\
\hline$\delta_{1} / A_{1}$ & $\begin{array}{l}\text { Ratio of storey displacement and } \\
\text { storey displacement average }\end{array}$ \\
\hline model $1 \mathrm{P}$ & Model 1 maximum seismic load \\
\hline model $2 \mathrm{P}$ & Model 2 maximum seismic load \\
\hline $\begin{array}{l}\text { model } \\
1 V_{1}, V_{2}\end{array}$ & Model 1 maximum shear forces \\
\hline $\begin{array}{l}\text { model } \\
1 V_{2}\end{array}$ & Model 2 maximum shear forces \\
\hline $\begin{array}{ll}\text { model } 1 \\
\mathrm{~T}\end{array}$ & Model 1 maximum torsion forces \\
\hline $\begin{array}{ll}\text { model } 2 \\
\mathrm{~T}\end{array}$ & Model 2 maximum torsion forces \\
\hline $\begin{array}{l}\text { model } \\
1 \mathrm{M}_{1}\end{array}$ & Model 1 maximum moment forces \\
\hline $\begin{array}{l}\text { model } \\
2 \mathrm{M}_{2}\end{array}$ & Model 2 maximum moment forces \\
\hline F1 & Shear forces in $\mathrm{X}$ direction in bases \\
\hline $\mathrm{F} 2$ & Shear forces in Y direction in bases \\
\hline F3 & Axial shear forces in $\mathrm{Z}$ direction in bases \\
\hline M1 & Moment forces around $\mathrm{X}$ axis \\
\hline M2 & Moment forces around Y axis \\
\hline M3 & Moment forces around $\mathrm{Z}$ axis \\
\hline
\end{tabular}

Table (1)

\section{REFERENCES}

[1]. Bao Shihua, Zhang Tongsheng,"Design and analysis of tall-building structure first edition"publisher 'Tsinghua University

[2]. Chinese Code for Seismic Design of Building, "GB50011-2010".

[3]. Mu Zhaohui, "SEISMIC ANALYSIS OF THE ASYMMETRIC HIGH-RISE BUILDING" South Jiaotong University, 2003.

[4]. He Junwei, "Research on Seismic Behavior of Irregular Frame Shear Wall Structure", (Zhejiang University), 2012. 
[5]. Mr.K.LovaRaju,Dr.K.V.G.D.Balaji, "Effective location of wall on performance of building frame subjected to earth load" International Advanced Reasearch Journal in Science, Engineering and Technology Vol. 2, Issue 1, January 2015

[6]. Fu Zhu Bian, Li Qi, Li Jia Hua, “建筑结构选型概念 "Wu Han Ligong University, 2003.

[7]. Bao Shihua, Zhang Tongsheng,"Design and analysis of tall-building structure first edition"publisher 'Tsinghua University

[8]. Wang Jingpeng, "Study of Dynamic Characteristics and Analysis of Seismic Response of Frame-shear Wall Structure” Chang an University, 2009. 